\title{
Nab-paclitaxel plus gemcitabine for metastatic pancreatic adenocarcinoma after Folfirinox failure: an AGEO prospective multicentre cohort
}

\author{
Alix Portal ${ }^{1,14}$, Simon Pernot ${ }^{1,14}$, David Tougeron ${ }^{2}$, Claire Arbaud ${ }^{3}$, Anne Thirot Bidault ${ }^{4}$, \\ Christelle de la Fouchardière ${ }^{5}$, Pascal Hammel ${ }^{6}$, Thierry Lecomte ${ }^{7}$, Johann Dréanic ${ }^{8}$, Romain Coriat ${ }^{8}$, \\ Jean-Baptiste Bachet ${ }^{9}$, Olivier Dubreuil ${ }^{9}$, Lysiane Marthey ${ }^{10}$, Laetitia Dahan ${ }^{11}$, Belinda Tchoundjeu $^{12}$, \\ Christophe Locher $^{13}$, Céline Lepère ${ }^{1}$, Franck Bonnetain ${ }^{3}$ and Julien Taieb* ${ }^{\star 1,14}$
}

${ }^{1}$ Department of Gastroenterology and Digestive Oncology, Georges Pompidou European Hospital, Assistance Publique-Hôpitaux de Paris (AP-HP), Paris Descartes University, Paris, France; ${ }^{2}$ Department of Gastroenterology, Poitiers University Hospital, Poitiers, France; ${ }^{3}$ Methodological and Quality of Life Unit in Oncology, Quality of Life and Cancer Clinical Research Platform, Besançon University Hospital, Besançon, France; ${ }^{4}$ Department of Gastroenterology, Kremlin Bicêtre Hospital, Assistance Publique-Hôpitaux de Paris (AP-HP), Paris Sud University, Le Kremlin Bicêtre, France; ${ }^{5}$ Department of Medical Oncology, Anticancer Center Leon Berard, Lyon I university, Lyon, France; ${ }^{6}$ Department of Digestive Oncology, Hospital Beaujon, Assistance Publique-Hôpitaux de Paris (AP-HP), Paris Denis Diderot University, Clichy, France; ${ }^{7}$ Department of Hepato-Gastroenterology and Digestive Oncology, University Hospital of Tours, UMR CNRS 7192, François-Rabelais University, Tours, France; ${ }^{8}$ Gastroenterology and Endoscopy Unit, Cochin Hospital, Assistance Publique-Hôpitaux de Paris (AP-HP), Paris Descartes University, Sorbonne Paris Cité, Paris, France; ${ }^{9}$ Department of Gastroenterology, La Pitié-Salpétrière Hospital, Assistance PubliqueHôpitaux de Paris (AP-HP), Sorbonne University, UPMC University Paris 06, Paris, France; ${ }^{10}$ Department of Hepatogastroenterology and Nutrition, Antoine-Béclère Hospital, Assistance publique-Hôpitaux de Paris (AP-HP), DHU Hepatinov, Clamart, France; ${ }^{11}$ Department of Gastroenterology, University Hospital La Timone, Aix-Marseille University, Marseille, France; ${ }^{12}$ Department of Gastroenterology and Digestive Oncology, Orleans Regional Hospital (CHRO), Orleans, France and ${ }^{13}$ Department of Gastroenterology, Meaux Hospital, Meaux, France

Background: There is currently no standard second-line treatment for metastatic pancreatic adenocarcinoma (MPA), and progression-free survival is consistently $<4$ months in this setting. The aim of this study was to evaluate the efficacy and tolerability of Nab-paclitaxel plus gemcitabine $(A+G)$ after Folfirinox failure in MPA.

Methods: From February 2013 to July 2014, all consecutive patients treated with A+ G for histologically proven MPA after Folfirinox failure were prospectively enrolled in 12 French centres. $A+G$ was delivered as described in the MPACT trial, until disease progression, patient refusal or unacceptable toxicity.

Results: Fifty-seven patients were treated with Nab-paclitaxel plus gemcitabine, for a median of 4 cycles (range 1-12). The disease control rate was $58 \%$, with a $17.5 \%$ objective response rate. Median overall survival (OS) was 8.8 months (95\% Cl: 6.2-9.7) and median progression-free survival was 5.1 months (95\% Cl: 3.2-6.2). Since the start of first-line chemotherapy, median OS was 18 months (95\% Cl: 16-21). No toxic deaths occurred. Grade 3-4 toxicities were reported in $40 \%$ of patients, consisting of neutropenia (12.5\%), neurotoxicity (12.5\%), asthenia (9\%) and thrombocytopenia (6.5\%).

Conclusions: $A+G$ seems to be effective, with a manageable toxicity profile, after Folfirinox failure in patients with MPA.

\footnotetext{
*Correspondence: Professor J Taieb; E-mail: jtaieb75@gmail.com

${ }^{14}$ These authors contributed equally to this work.
}

Received 28 April 2015; revised 7 July 2015; accepted 13 August 2015; published online 15 September 2015

(C) 2015 Cancer Research UK. All rights reserved 0007 - 0920/15 
Pancreatic adenocarcinoma is a frequent malignancy with an overall 5-year survival rate of only about 6\% (Sant et al, 2009; Siegel et al, 2012). Its incidence has gradually increased over the past 10 years, and $>360000$ new cases are projected worldwide in 2015 (Globocan). Metastatic pancreatic adenocarcinoma (MPA) is one of the most rapidly lethal gastrointestinal malignancies. Without treatment, the median survival time is consistently $<6$ months (Hidalgo, 2010), and new therapeutic options are therefore needed. Since 1997, gemcitabine has been the standard treatment for MPA, giving a median survival of approximately 7 months. Some advances have been made during the past 4 years, including positive results in two phase III trials of first-line Folfirinox (5fluorouracil, oxaliplatin, irinotecan, leucovorin) (Conroy et al, 2011) and Nab-paclitaxel plus gemcitabine (Von Hoff et al, 2013). Both Folfirinox and Nab-paclitaxel plus gemcitabine were more effective than gemcitabine alone in terms of progression-free survival (PFS) and overall survival (OS), raising questions as to the treatment choice and sequence. We therefore conducted a multicentre, prospective cohort study to assess the efficacy and tolerability of Nab-paclitaxel plus gemcitabine after failure of first-line Folfirinox in patients with MPA. Folfirinox was administered first because it is currently the standard first-line treatment in France and because guidelines stipulate the need for an Eastern Cooperative Oncology Group performance status (ECOG-PS) score of 0 or 1 and normal bilirubinemia, whereas Nab-paclitaxel plus gemcitabine can be administered to frailer patients.

\section{PATIENTS AND METHODS}

Patients. All consecutive MPA patients treated with Nab-paclitaxel plus gemcitabine after Folfirinox failure between February 2013 and July 2014 in 12 French AGEO (Association des GastroEntérologues Oncologues) centres were prospectively enrolled in our database. To be eligible, patients had to be at least 18 years, have an ECOG-PS score of 0,1 or 2, have histologically or cytologically proven PA with measurable metastatic lesion(s) according to RECIST criteria V1.1 and have received Folfirinox as first-line palliative therapy. The administration of Nab-paclitaxel plus gemcitabine as second-line chemotherapy was decided in each centre, following validation by a multidisciplinary meeting. Patients having received chemotherapy regimens other than Folfirinox were not eligible for the study. As Nab-paclitaxel plus gemcitabine is an approved first-line regimen yielding favourable response and survival rates, and as there is no standard second-line treatment after Folfirinox failure, our institutional review board approved the use of Nab-paclitaxel plus gemcitabine as second-line therapy.

Tumour assessment. The following tumour-related information was collected: date of diagnosis, size of the primary tumour in millimetres, its location (head, body or tail of the pancreas), and the number and location of metastases. Initial evaluation included carbohydrate antigen 19-9 (CA 19-9) assay.

Treatment. The following characteristics of first-line Folfirinox were collected: number of cycles, reasons for treatment cessation, and best response (RECIST v1.1).

Each cycle of Nab-paclitaxel plus gemcitabine consisted of a 60 min intravenous infusion of Nab-paclitaxel at a dose of $125 \mathrm{mg} \mathrm{m}^{-2}$, followed by a 30 -min infusion of gemcitabine at a dose of $1000 \mathrm{mg} \mathrm{m}^{-2}$ on days 1,8 , and 15 every 4 weeks, as described for first-line treatment (Von Hoff et al, 2013). This regimen was delivered until disease progression, unacceptable toxicity or patient refusal.

Primary prophylaxis of neutropenia with granulocyte colonystimulating factor (G-CSF) was left to each physician's discretion.
Outcome measures. Adverse events, the date of the first infusion of Nab-paclitaxel plus gemcitabine and the number of cycles administered were recorded. Tolerability was assessed by recording all chemotherapy-related adverse events that occurred during the study. Nausea and vomiting, diarrhoea, fatigue, sensory neuropathy, hand-foot syndrome, mucositis, alopecia, neutropenia, thrombocytopenia and anaemia were evaluated with the National Cancer Institute Common Terminology Criteria for Adverse Events (NCI-CTCAE) V4.03. Serious adverse events, including treatment-related deaths, grade 3 or 4 toxicities and withdrawals for toxicity, and dose reductions for adverse events were recorded.

Treatment efficacy was assessed every 2 months by chestabdomen-pelvis computed tomography (CT) using RECIST version1.1 criteria (Therasse et al, 2000) and by CA 19-9 monitoring as recommended by the French national cancer institute and national guidelines. Any third-line chemotherapy administered after disease progression was recorded. After progression, all patients were followed up until death.

Statistical analysis. Patient data were prospectively recorded in the database. Quantitative data were expressed as medians (range) and qualitative data as percentages. As this was a prospective observational cohort, no sample size calculation was necessary. However, we calculated the necessary sample size and halted data collection when it had been reached. Using one-arm nonparametric survival methodology, with 57 patients included over 17 months and with 18 months of follow-up, we would achieve $92 \%$ statistical power with a bilateral alpha type 1 error of $5 \%$ to demonstrate that the PFS rate at 6 months was $>20 \%(\mathrm{H} 0)$, with an expected rate of $40 \%$ (H1). Lower and upper critical values would be, respectively, $12 \%$ and $34 \%$.

A clinical response was defined as an improvement in symptoms present at the beginning of treatment and was based on the investigators' evaluation. The objective response rate was calculated as the sum of complete and partial responses. The disease control rate was defined as the sum of complete and partial responses and stable disease. In agreement with the DATECAN consensus (Bonnetain et al, 2014), PFS was defined as the time between the first Nab-paclitaxel plus gemcitabine administration and disease progression or death (all causes), whichever occurred first. OS was defined from the start of Nab-paclitaxel plus gemcitabine chemotherapy until death (all causes). To assess the overall treatment strategy, $\mathrm{PFS}_{1+2}$ and $\mathrm{OS}_{1+2}$ were calculated from the beginning of Folfirinox therapy until a corresponding event occurred during or after Nab-paclitaxel plus gemcitabine administration. Patients without events were censored at the last follow-up date. Survival curves were estimated with the KaplanMeier method. Median follow-up was calculated with the reverse Kaplan-Meier method. All analyses were performed with a twosided type 1 error of $5 \%$.

\section{RESULTS}

Patient and tumour characteristics. During the recruitment period, 110 patients stopped Folfirinox for progression or toxicity, and $77(70 \%)$ of them were eligible to receive Nab-paclitaxel plus gemcitabine. Twenty patients were excluded from the present study because of locally advanced/non-metastatic disease and two for other reasons (PS $>2$ ). The study population thus consisted of 57 patients, whose baseline characteristics are summarised in Table 1. Most patients had an ECOG-PS score of 1 or 2 . The median number of Folfirinox cycles received was 12. Nabpaclitaxel plus gemcitabine was usually started because of disease progression (95\%). Most tumours were located in the head of the pancreas, and most patients had only one metastatic site. 
Tolerability. In September 2014 (cutoff date for this analysis), 248 cycles of Nab-paclitaxel plus gemcitabine had been administered (median per patient: 4, range: 1-12). No toxic deaths occurred. Treatment was stopped in 42 patients (74\%) because of disease progression $(n=40)$ or unacceptable toxicity ( $n=2$ : grade 4 thrombocytopenia; grade 3 asthenia). Toxicities are described in Table 2. Grade 3-4 toxicities occurred in 21 patients $(38 \%)$.

Thirty-eight patients (67\%) had a transient or permanent dose reduction (gemcitabine 49\%, Nab-paclitaxel 64\%) because of asthenia (32\%), hematological toxicities (45\%) or peripheral neurotoxicity (29\%). Peripheral neurotoxicity usually consisted of reversible paresthesia and/or hypoesthesia. Seven patients (12.5\%) had to stop Nab-paclitaxel permanently because of peripheral neurotoxicity $(n=4)$, hematological toxicity $(n=2)$ or asthenia $(n=1)$.

Efficacy. Patients survival and tumour responses are summarised in Table 3.

RECIST assessment was possible in 54 of the 57 patients (1 patient received only two administrations of chemotherapy, and follow-up CT scans were not performed in 2 patients). Objective responses were observed in 10 patients $(17.5 \%$ in the intention-totreat population (ITT)) and disease stabilisation occurred in 23 patients (40.5\%, ITT population), giving a disease control rate of 58\% (95\% CI: 45-71).

A clinical response was observed in 19 patients (33\%), clinical stability in 21 patients (37\%) and clinical progression in 17 patients (30\%). Symptoms reported before Nab-paclitaxel plus gemcitabine were mainly abdominal pain (33\%), asthenia (19\%) and ascitis (5\%). They were not precisely described for 24 patients (42\%). Nab-paclitaxel plus gemcitabine resulted in an improvement in pain and asthenia in $63 \%$ of patients.

After a median follow-up of 17.5 months (range 5-45) since the beginning of Folfirinox and 6 months (range 0.7-16 months) since the beginning of Nab-paclitaxel plus gemcitabine, median OS was 8.8 months (95\% CI: 6.2-9.7). The OS rates at 6 and 12 months were, respectively, 69\% (95\% CI: 0.53-0.80) and $15 \%$ (95\% CI: 0.03-0.36). Median PFS was 5.1 months (95\% CI: 3.2-6.2). The PFS rates at 6 and 12 months were, respectively, 39\% (95\% CI: $0.25-0.52$ ) and 6\% (95\% CI: 0.01-0.23) (Figure 1).

We performed univariate and multivariate analysis to identify factors associated with better outcome in these patients treated with Nab-paclitaxel plus gemcitabine. None of the following factors: age, body mass index, ECOG-PS score (1 or 2 vs 0 ), number of metastasic sites ( 2 or 3 vs 1 ), bilirubin and Ca19-9 levels impacted survival (Supplementary Table S1). The response to Nabpaclitaxel plus gemcitabine was not influenced by the prior response to first-line Folfirinox. Indeed, there was no statistical difference in PFS between patients who had a partial response, stable disease or progressive disease as the best response to Folfirinox, and a trend was noted towards worse PFS in patients who previously responded well to Folfirinox. PFS with Nabpaclitaxel plus gemcitabine was significantly better in patients with a PFS value lower than the median with Folfirinox (Supplementary Figure S1).

Median survival since the beginning of first-line chemotherapy (Folfirinox) was 14 months (95\% CI: 12.8-15.4) and 18 months (95\% CI: 16-21.2) for $\mathrm{PFS}_{1+2}$ and $\mathrm{OS}_{1+2}$, respectively (Figure 2). The $\mathrm{OS}_{1+2}$ rates at 12 and 24 months were, respectively, $82 \%$ (95\% CI: $0.68-0.90)$ and $30 \%(0.14-0.47)$. After disease progression on Nab-paclitaxel plus gemcitabine, 15 patients (37.5\%) received best supportive care and 25 patients $(62.5 \%)$ received a third line of chemotherapy. Ten (40\%) of the latter patients received a fluoropyrimidine plus a platinum salt (oxaliplatin or cisplatin): 5 patients $(20 \%)$ received Folfirinox; 3 patients (12\%) received a
Table 1. Characteristics of the patients and tumours

$N=57(\%)$

\begin{tabular}{|c|c|}
\hline & $\mathbf{N}=\mathbf{5 7}(\%)$ \\
\hline \multicolumn{2}{|l|}{ Sex } \\
\hline Male & $27(47)$ \\
\hline Female & $30(53)$ \\
\hline Age (years; median (range)) & 59.9 (35-92) \\
\hline \multicolumn{2}{|l|}{ ECOG-PS } \\
\hline 0 & $9(16)$ \\
\hline 1 & $36(63)$ \\
\hline 2 & $12(21)$ \\
\hline \multicolumn{2}{|l|}{ Pancreatic tumour location } \\
\hline Head & $32(56)$ \\
\hline Body & $14(25)$ \\
\hline Tail & $9(16)$ \\
\hline Body and tail & $2(4)$ \\
\hline \multicolumn{2}{|l|}{ Metastatic sites } \\
\hline Liver - (exclusive) & $41(72)-(21(37))$ \\
\hline Peritoneum & $21(37)$ \\
\hline Lung & $11(19)$ \\
\hline Distant lymph nodes & $6(11)$ \\
\hline Bone & $2(4)$ \\
\hline Pleura & $2(4)$ \\
\hline \multicolumn{2}{|l|}{ Number of metastatic sites } \\
\hline 1 & $36(63)$ \\
\hline 2 & $16(28)$ \\
\hline$\geqslant 3$ & $5(9)$ \\
\hline Biliary stent & $17(29 \%)$ \\
\hline First-line chemotherapy & Folfirinox \\
\hline $\begin{array}{l}\text { Number of first-line chemotherapy cycles, } \\
\text { median (range) }\end{array}$ & $12(1-40)$ \\
\hline \multicolumn{2}{|l|}{ First-line treatment efficacy } \\
\hline Complete response & $0(0)$ \\
\hline Partial response & $22(39)$ \\
\hline Stable disease & $18(32)$ \\
\hline Progressive disease & $16(28)$ \\
\hline Unknown & $1(1)$ \\
\hline \multicolumn{2}{|l|}{ First-line treatment interruption for } \\
\hline Progression & $54(95)$ \\
\hline Toxicity & $3(5)$ \\
\hline Other & $0(0)$ \\
\hline \multicolumn{2}{|l|}{ Oxaliplatin neurotoxicity } \\
\hline Yes & $9(16)$ \\
\hline No & $48(84)$ \\
\hline
\end{tabular}

Folfiri-3 regimen; 2 patients (8\%) received gemcitabine plus erlotinib; and 5 patients $(20 \%)$ received other regimens in early-phase clinical trials.

\section{DISCUSSION}

There is no consensus second-line chemotherapy regimen (Rahma et al, 2013) for MPA patients, and the second-line treatment choice should take into account the first-line treatment, of which several effective options are available, including Folfirinox (Conroy et al, 2011) and Nab-paclitaxel plus gemcitabine (Von Hoff et al, 2013). Indeed, these two regimens have not been compared in the firstline setting. Biomarkers (hENT1and ERCC1) (Maréchal et al, 2012; Peters et al, 2014) might help to choose between first-line gemcitabine- or platinum-based regimens but have not yet been validated. This means that currently the best first-line treatment 
Table 2. Safety evaluated according to the National Cancer Institute Common Terminology Criteria for Adverse Events ( $\mathrm{NCl}-\mathrm{CTCAE}$ ) V4.03

\begin{tabular}{|c|c|c|c|c|c|}
\hline & Grade 0 & Grade 1 & Grade 2 & Grade 3 & Grade 4 \\
\hline Nausea and vomiting & $40(70)$ & $9(16)$ & $6(10.5)$ & $2(3.5)$ & $0(0)$ \\
\hline Diarrhoea & $40(70)$ & $12(21)$ & $4(7)$ & $1(2)$ & $0(0)$ \\
\hline Fatigue & $13(23)$ & $24(42)$ & $15(26)$ & $5(9)$ & $0(0)$ \\
\hline Neurotoxicity & $12(21)$ & $20(35)$ & $18(31.5)$ & $7(12.5)$ & $0(0)$ \\
\hline Hand-foot syndrome & $57(100)$ & $0(0)$ & $0(0)$ & $0(0)$ & $0(0)$ \\
\hline Mucositis & $50(88)$ & $5(9)$ & $1(1.5)$ & $1(1.5)$ & $0(0)$ \\
\hline Alopecia & $25(44)$ & $3(5)$ & $29(51)$ & I & I \\
\hline Neutropenia & $30(52.5)$ & $10(17.5)$ & $10(17.5)$ & $7(12.5)$ & $0(0)$ \\
\hline Thrombocytopenia & $34(60)$ & $9(16)$ & $10(17.5)$ & $3(5)$ & $1(1.5)$ \\
\hline Anaemia & $21(37)$ & $22(38.5)$ & $12(21)$ & $2(3.5)$ & $0(0)$ \\
\hline Maximal toxicity & $0(0)$ & $2(3)$ & $34(59.5)$ & $20(36)$ & $1(1.5)$ \\
\hline
\end{tabular}

Table 3. Efficacy of Gemcitabine with Nab-paclitaxel

\begin{tabular}{|c|c|c|}
\hline & $N(\%)$ & $95 \% \mathrm{Cl}$ \\
\hline \multicolumn{3}{|l|}{ RECIST v1.1 criteria } \\
\hline Complete response & $0(0)$ & 0 \\
\hline Partial response & $10(17.5)$ & $8-29$ \\
\hline Stable disease & $23(40.5)$ & $29-56$ \\
\hline Progressive disease & $21(37)$ & $25-52$ \\
\hline Not assessable & $3(5)$ & \\
\hline Disease control rate & $33(58)$ & $45-71$ \\
\hline \multicolumn{3}{|l|}{ Clinical response } \\
\hline Amelioration & $19(33)$ & $21.1-45.6$ \\
\hline Stability & $21(37)$ & $24.3-49.4$ \\
\hline Progression & $17(30)$ & $17.9-41.7$ \\
\hline Median progression-free survival & 5.1 months (40 events) & $3.2-6.2$ \\
\hline Median overall survival & 8.8 months (27 events) & $6.2-9.7$ \\
\hline
\end{tabular}

and the therapeutic sequence are unknown and our daily practice is guided solely by patient characteristics. In this context, we decided to study the sequence used in many centres, notably in France, namely first-line Folfirinox followed by gemcitabine-based second-line chemotherapy. Strategies based on Folfirinox followed by Nab-paclitaxel plus gemcitabine, or the reverse sequence, have not previously been tested. Folfirinox seems easier to administer first, when patients are still in relatively good general condition, including normal bilirubinemia, while Nab-paclitaxel plus gemcitabine may be a better-tolerated option for more fragile patients, notably those with a Karnofsky index of 70-80\% (Von Hoff et al, 2013). In addition, the acceptable tolerability of $\mathrm{Nab}$-paclitaxel plus gemcitabine, together with a few reports of efficacy in second-line treatment (Portal et al, 2014; Giordano et al (2014)), makes it a good candidate treatment for patients having received Folfirinox.

In our selected patient population, the observed median PFS and OS with Nab-paclitaxel plus gemcitabine were, respectively, 5.1 and 8.8 months. We confirmed our statistical hypothesis, with a 6-month PFS of 39\% (95\% CI: 0.25-0.52). Moreover, median OS from the beginning of first-line treatment was 18 months. Although our strategy seems very promising, we cannot compare survival with that of other first-line trials, as we selected only patients able to receive first-line Folfirinox and a relatively intensive second-line treatment. Interestingly, the response to first-line Folfirinox did not influence the response to Nab-paclitaxel plus gemcitabine. The disease control rate was

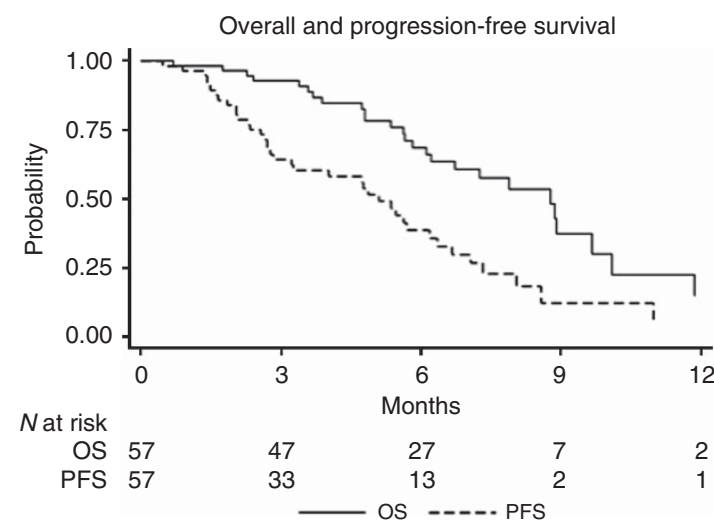

Figure 1. OS and PFS.

Overall and progression-free survival since the beginning of first-line chemotherapy

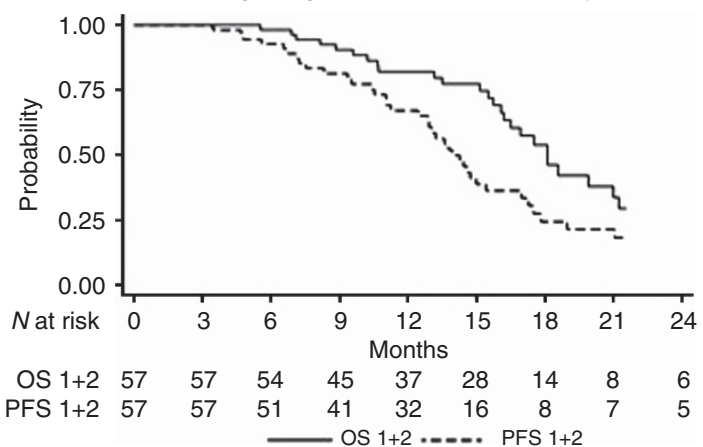

Figure 2. OS and PFS since the beginning of first-line chemotherapy. $\mathrm{OS}_{1+2}$ : Overall survival since the beginning of first-line chemotherapy. $\mathrm{PFS}_{1+2}$ : Progression-free survival since the beginning of first-line chemotherapy.

$58 \%$. With a median follow-up of 6 months, 39\% and $6 \%$ of patients were still controlled at 6 and 12 months, respectively. Among patients who progressed, $62.5 \%$ received a third line of chemotherapy.

Many drugs have been tested in second-line chemotherapy regimens for MPA, in phase II and even phase III trials. The results are summarised in Table 4. 5-FU, folinic acid and oxaliplatin 
Table 4. Summary of second-line chemotherapy studies in metastatic pancreatic adenocarcinoma

\begin{tabular}{|c|c|c|c|c|c|}
\hline & $\begin{array}{l}\text { No. of } \\
\text { patients }\end{array}$ & First line & Second line & $\begin{array}{l}\text { Median PFS } \\
\text { (months) }\end{array}$ & $\begin{array}{l}\text { Median OS } \\
\text { (months) }\end{array}$ \\
\hline Pelzer et al, $2011^{\mathrm{a}}$ & 46 & Gemcitabine & OFF & NA & 4.82 \\
\hline \multirow[t]{2}{*}{ Oettle et al, 2014 } & 168 & Gemcitabine & OFF & 2.9 & 5.9 \\
\hline & & & LV5-FU2 & 2 & 3.3 \\
\hline \multirow[t]{2}{*}{ Yoo et al, 2009b } & 61 & Gemcitabine & FOLFIRI-3 & 2 & 4.2 \\
\hline & & & FOLFOX & 1.5 & 3.7 \\
\hline Zaanan et al, 2014c & 46 & Gemcitabine alone or alternating with Folfiri-3 & FOLFOX & 1.7 & 4.3 \\
\hline \multirow[t]{2}{*}{ Gill et al, 2014 } & 108 & Gemcitabine-based therapy & LV5-FU2 & 2.9 & 9.9 \\
\hline & & & FOLFOX & 3.1 & 6.1 \\
\hline \multirow[t]{2}{*}{ Von Hoff et al, 2013 } & & Gemcitabine-based therapy & LV5-FU2 MM-398 & 3.1 & 6.1 \\
\hline & & & LV5-FU2 & 1.5 & 4.2 \\
\hline \multirow[t]{2}{*}{ Dahan et al, 2010 } & 202 & LV5-FU2 + CDDP & Gemcitabine & 2.3 & \\
\hline & & Gemcitabine & LV5-FU2 + CCDP & 2.6 & \\
\hline Soares et al, 2014 ${ }^{b}$ & 42 & Gemcitabine-based therapy & Capecitabine + Docetaxel & 3.7 & 5.3 \\
\hline Hosein et al, $2013^{b}$ & 19 & Gemcitabine-based therapy & Nab-paclitaxel & 1.7 & 7.3 \\
\hline Portal et al, 2014 & 57 & Folfirinox & Nab-paclitaxel & 5.1 & 8.8 \\
\hline \multicolumn{6}{|c|}{$\begin{array}{l}\text { Abbreviations: } \mathrm{CDDP}=\text { cisplatin; } \mathrm{NA}=\text { not available; } \mathrm{OS}=\text { overall survival; } \mathrm{PFS}=\text { progression-free survival. } \\
\text { a Phase } 3 \text { trial. } \\
\mathrm{b}_{\text {Phase } 2 \text { trial. }} \\
\mathrm{c}_{\text {Prospective observational cohort. }}\end{array}$} \\
\hline
\end{tabular}

combinations (OFF or FOLFOX) (Yoo et al, 2009; Pelzer et al, 2011; Oettle et al, 2014; Zaanan et al, 2014) had the best supporting evidence after failure of gemcitabine-based first-line treatment, despite some recent controversy (Gill et al, 2014). It should be noted that the two regimens used in these trials were slightly different, especially concerning the 5-FU dosage and administration. This may have had a role in the different outcomes reported in these two studies. In selected populations, Folfirinox has been tested in two retrospective studies, with an OS of about 8.5 months (Assaf et al, 2011; Lee et al, 2013). Recently, the NAPOLI-1 trial showed the superiority of a combination of 5-FU and MM-398 (injectable liposomal irinotecan) over 5-FU alone (Von Hoff et al (2014)). In the FFCD 0301 trial, gemcitabine was well tolerated as second-line therapy after a 5-FU-platinum doublet (Dahan et al, 2010), but median PFS was only 2.3 months (95\% CI 1.9-3). Two recent phase II trials tested second-line taxane therapy. In the first, PFS and OS were 3.7 and 5.3 months, respectively, with the capecitabine-docetaxel combination (Soares et al, 2014). In the second, PFS and OS were 1.7 and 7.3 months, respectively, with Nab-paclitaxel monotherapy (Hosein et al, 2013). Therefore, within the limits of an indirect comparison, OS and PFS appear to be better with second-line Nab-paclitaxel plus gemcitabine.

No toxic deaths occurred in patients receiving Nab-paclitaxel plus gemcitabine. Grade 3-4 toxicities occurred in 21 patients $(37.5 \%)$ and consisted mainly of haematological adverse effects (neutropenia: 12.5\%; thrombocytopenia: 6.5\%; anaemia: $3.5 \%$ ), asthenia (9\%) and neurotoxicity (12.5\%). These results are comparable with those reported with Nab-paclitaxel plus gemcitabine first-line chemotherapy (Von Hoff et al, 2013) and with other second-line regimens (10-38\% of grade 3-4 toxicity). One of the main concerns with our therapeutic sequence is the risk of severe chronic peripheral sensory neurotoxicity owing to the use of neurotoxic agents such as Nab-paclitaxel after oxaliplatin. Neuropathy has been reported in $4 \%$ of patients treated with second-line taxane-based regimens (Soares et al, 2014) and in $0-7.5 \%$ of patients treated with oxaliplatin-based regimens (Yoo et al, 2009; Pelzer et al, 2011; Oettle et al, 2014; Zaanan et al, 2014). Severe sensory neurotoxicity affected $12.5 \%$ of our patients and led to permanent Nab-paclitaxel discontinuation in five cases. This toxicity rate is quite low compared with the MPACT trial, even though our patients were receiving second-line treatment. As this was an observational study, dose modifications were not standardised and dose reductions were made earlier than during first-line treatment. Indeed, as this was second-line therapy, and as there was a confounding aetiology of neuropathy (oxaliplatin or Nab-paclitaxel), drug management was more cautious than in the first-line setting. Nab-paclitaxel was reduced or stopped earlier and more frequently than in the MPACT trial. Indeed, the Nabpaclitaxel dose was reduced in $54 \%$ of patients (compared with $41 \%$ in MPACT), and only 59\% of all Nab-paclitaxel administrations involved the full dose ( $71 \%$ in MPACT). Furthermore, the mechanisms of oxaliplatin and Nab-paclitaxel neurotoxicity are different, and so is their reversibility. Oxaliplatin causes symmetrical paresthesia and distal hypoesthesia that can lead to difficulties in daily life activities, and this toxicity can worsen even after treatment cessation and last for several years. Nab-paclitaxel also causes paresthesia, as well as distal burning pain, but the symptoms generally improve within 2 months after treatment cessation (Scripture et al, 2006). Therefore, despite an equivalent grade, the impact of Nab-paclitaxel neurotoxicity on patients' quality of life may be less severe. This is supported by the results of Safran et al (2014) showing that patients treated with a combination of FOLFOX and Nab-Paclitaxel did not develop significant neuropathy when they received fewer than 10 cycles, which is consistent with the occurrence of neuropathy with FOLFOX alone. With a median of less than 5 cycles per patient in our study, the risk seems limited.

The main limitation of this prospective multicentre study is its observational nature. Treatment decisions, such as dose reductions and prophylactic use of G-CSF, were left to the discretion of the physicians in different centres, as was treatment discontinuation. These decisions could have impacted the efficacy and safety results. Moreover, our population was highly selected, as patients had to be able to receive first-line Folfirinox and only patients with a ECOG-PS of 0,1 or 2 after Folfirinox failure were enrolled. Altogether, $63 \%$ of the patients treated with first-line Folfirinox and with a metastatic disease were eligible for the present study. This percentage compares favourably with $<50 \%$ reported 
elsewhere. Our patients seem representative of the general population of patients in this setting. Indeed, Folfirinox is widely used as first-line treatment in France, and $<50 \%$ of patients treated for pancreatic adenocarcinoma are reported to be eligible for second-line treatment (Bachet et al, 2009), whatever the firstline regimen, even among selected patients from the most recent therapeutic trials (Conroy et al, 2011; Von Hoff et al, 2013).This selection bias seems to be a consistent feature of second-line studies and also in routine clinical practice. We enrolled patients with an ECOG-PS of 2, without strong exclusion criteria, contrary to many previous studies. Another limitation of our study is the lack of quality-of-life evaluation, which is an important element of palliative chemotherapy for pancreatic cancer.

\section{CONCLUSION}

With a median PFS of 5.1 months and a median OS of 8.8 months, the Nab-paclitaxel and gemcitabine combination seems promising for second-line treatment of patients with MAP who are in good general condition after Folfirinox failure. The main adverse effects are peripheral neuropathy, neutropenia, thrombocytopenia and fatigue. These promising results need to be confirmed in a comparative randomised trial.

\section{CONFLICT OF INTEREST}

The authors declare no conflict of interest.

REFERENCES

Assaf E, Verlinde-Carvalho M, Delbaldo C, Grenier J, Sellam Z, Pouessel D, Bouaita L, Baumgaertner I, Sobhani I, Tayar C, Paul M, Culine S (2011) 5-fluorouracil/leucovorin combined with irinotecan and oxaliplatin (FOLFIRINOX) as second-line chemotherapy in patients with metastatic pancreatic adenocarcinoma. Oncology 80: 301-306.

Bachet J-B, Mitry E, Lièvre A, Lepère C, Vaillant J-N, Declety G, Parlier H, Emile J-F, Julié C, Rougier P (2009) Second- and third-line chemotherapy in patients with metastatic pancreatic adenocarcinoma: feasibility and potential benefits in a retrospective series of 117 patients. Gastroenterol Clin Biol 33: 1036-1044.

Bonnetain F, Bonsing B, Conroy T, Dousseau A, Glimelius B, Haustermans K, Lacaine F, Van Laethem JL, Aparicio T, Aust D, Bassi C, Berger V, Chamorey E, Chibaudel B, Dahan L, De Gramont A, Delpero JR, Dervenis C, Ducreux M, Gal J, Gerber E, Ghaneh P, Hammel P, Hendlisz A, Jooste V, Labianca R, Latouche A, Lutz M, Macarulla T, Malka D, Mauer M, Mitry E, Neoptolemos J, Pessaux P, Sauvanet A, Tabernero J, Taieb J, van Tienhoven G, Gourgou-Bourgade S, Bellera C, Mathoulin-Pélissier S, Collette L (2014) Guidelines for time-to-event end-point definitions in trials for pancreatic cancer. Results of the DATECAN initiative (Definition for the Assessment of Time-to-event End-points in CANcer trials). Eur J Cancer 50: 2983-2993.

Conroy T, Desseigne F, Ychou M, Bouché O, Guimbaud R, Bécouarn Y, Adenis A, Raoul J-L, Gourgou-Bourgade S, de la Fouchardière C, Bennouna J, Bachet J-B, Khemissa-Akouz F, Péré-Vergé D, Delbaldo C, Assenat E, Chauffert B, Michel P, Montoto-Grillot C, Ducreux M. Groupe Tumeurs Digestives of UnicancerPRODIGE Intergroup (2011) FOLFIRINOX versus gemcitabine for metastatic pancreatic cancer. N Engl J Med 364: 1817-1825.

Dahan L, Bonnetain F, Ychou M, Mitry E, Gasmi M, Raoul J-L, Cattan S, Phelip J-M, Hammel P, Chauffert B, Michel P, Legoux J-L, Rougier P, Bedenne L, Seitz J-F. Fédération Francophone de Cancérologie Digestive (2010) Combination 5-fluorouracil, folinic acid and cisplatin (LV5FU2-CDDP) followed by gemcitabine or the reverse sequence in metastatic pancreatic cancer: final results of a randomised strategic phase III trial (FFCD 0301). Gut 59: 1527-1534.

Gill S, Ko Y-J, Cripps C, Beaudoin A, Dhesy-Thind B, Zulfiqar M, Zalewski P, Do T, Cano P, Yin Han Lam W, Dowden S, Grassin H, Stewart J,
Moore M (2014) PANCREOX: A randomized phase 3 study of 5FU/LV with or without oxaliplatin for second-line advanced pancreatic cancer (APC) in patients (pts) who have received gemcitabine (GEM)-based chemotherapy (CT). J Clin Oncol 32: 5s (suppl; abstr 4022).

Giordano G, Miella M, Melisi D, Zaniboni A, Zagonel V, Caponi S, Giommoni E, Santoni M, Vaccaro V, Bertocchi P, Bergamo F, Molinara E, Musettini G, Lucchini E, Febbraro A (2014) Nab-Paclitaxel and Gemcitabine in pretreated advanced pancreatic cancer patients: a multicentre retrospective analysis. Ann Oncol 25(Suppl 4): iv210-iv253.

Hidalgo M (2010) Pancreatic cancer. N Engl J Med 362: 1605-1617.

Hosein PJ, de Lima Lopes G, Pastorini VH, Gomez C, Macintyre J, Zayas G, Reis I, Montero AJ, Merchan JR, Rocha Lima CM (2013) A phase II trial of nab-Paclitaxel as second-line therapy in patients with advanced pancreatic cancer. Am J Clin Oncol 36: 151-156.

Lee MG, Lee SH, Lee SJ, Lee YS, Hwang J-H, Ryu JK, Kim Y-T, Kim DU, Woo SM (2013) 5-Fluorouracil/leucovorin combined with irinotecan and oxaliplatin (FOLFIRINOX) as second-line chemotherapy in patients with advanced pancreatic cancer who have progressed on gemcitabine-based therapy. Chemotherapy 59: 273-279.

Maréchal R, Bachet J-B, Mackey JR, Dalban C, Demetter P, Graham K, Couvelard A, Svrcek M, Bardier-Dupas A, Hammel P, Sauvanet A, Louvet C, Paye F, Rougier P, Penna C, André T, Dumontet C, Cass CE, Jordheim LP, Matera E-L, Closset J, Salmon I, Devière J, Emile J-F, Van Laethem J-L (2012) Levels of gemcitabine transport and metabolism proteins predict survival times of patients treated with gemcitabine for pancreatic adenocarcinoma. Gastroenterology 143: 664-674.e1-e6.

Oettle H, Riess H, Stieler JM, Heil G, Schwaner I, Seraphin J, Görner M, Mölle M, Greten TF, Lakner V, Bischoff S, Sinn M, Dörken B, Pelzer U (2014) Second-line oxaliplatin, folinic acid, and fluorouracil versus folinic acid and fluorouracil alone for gemcitabine-refractory pancreatic cancer: outcomes from the CONKO-003 trial. J Clin Oncol 32: 2423-2429.

Pelzer U, Schwaner I, Stieler J, Adler M, Seraphin J, Dörken B, Riess H, Oettle H (2011) Best supportive care (BSC) versus oxaliplatin, folinic acid and 5-fluorouracil (OFF) plus BSC in patients for second-line advanced pancreatic cancer: a phase III-study from the German CONKO-study group. Eur J Cancer 47: 1676-1681.

Peters GJ, Avan A, Ruiz MG, Orsini V, Avan A, Giovannetti E, Smit EF (2014) Predictive role of repair enzymes in the efficacy of Cisplatin combinations in pancreatic and lung cancer. Anticancer Res 34: 435-442.

Portal A, Pernot S, Siauve N, Landi B, Lepère C, Colussi O, Rougier P, Zaanan A, Verrière B, Taieb J (2014) Sustained response with gemcitabine plus Nab-paclitaxel after folfirinox failure in metastatic pancreatic cancer: report of an effective new strategy. Clin Res Hepatol Gastroenterol 38: e23-e26.

Rahma OE, Duffy A, Liewehr DJ, Steinberg SM, Greten TF (2013) Second-line treatment in advanced pancreatic cancer: a comprehensive analysis of published clinical trials. Ann Oncol 24: 1972-1979.

Safran H, Perez K, Charpentier K, Austin TC, Mantripragada K, Bishop K, Lombardo A, Houlihan L, Mitchell K, Rosati K, Martel D, Shaw L (2014) Nab-paclitaxel combined with Folfox for advanced pancreatic cancer: a phase I study. J Clin Oncol 32: 5s (suppl; abstr 4123).

Sant M, Allemani C, Santaquilani M, Knijn A, Marchesi F, Capocaccia R. EUROCARE Working Group (2009) EUROCARE-4. Survival of cancer patients diagnosed in 1995-1999. Results and commentary. Eur J Cancer 45: 931-991.

Scripture CD, Figg WD, Sparreboom A (2006) Peripheral neuropathy induced by paclitaxel: recent insights and future perspectives. Curr Neuropharmacol 4: 165-172.

Siegel R, Naishadham D, Jemal A (2012) Cancer statistics, 2012. CA Cancer J Clin 62: 10-29.

Soares HP, Bayraktar S, Blaya M, Lopes G, Merchan J, Macintyre J, Mayo C, Green MR, Silva O, Levi J, Walker G, Rocha-Lima CM (2014) A phase II study of capecitabine plus docetaxel in gemcitabine-pretreated metastatic pancreatic cancer patients: CapTere. Cancer Chemother Pharmacol 73: 839-845.

Therasse P, Arbuck SG, Eisenhauer EA, Wanders J, Kaplan RS, Rubinstein L, Verweij J, Van Glabbeke M, van Oosterom AT, Christian MC, Gwyther SG (2000) New guidelines to evaluate the response to treatment in solid tumors. European Organization for Research and Treatment of Cancer, National Cancer Institute of the United States, National Cancer Institute of Canada. J Natl Cancer Inst 92: 205-216.

Von Hoff D, Li C-P, Wang-Gillam A, Bodoky G, Dean A, Jameson G, Macarulla T, Lee K-H, Cunningham D, Blanc J-F, Hubner R, Chiu C-F, Schwartsmann G, 
Siveke J, Braiteh F, Moyo V, Belanger B, Dhindsa N, Bayever E, Chen L-T (2014) NAPOLI-1: randomized phase 3 study of MM-398 (NAL-IRI), with or without 5-Fluorouracil and leucovorin, versus 5-Fluorouracil and leucovorin, in metastatic pancreatic cancer progressed on or following gemcitabine-based therapy. Ann Oncol 25(Suppl 2): ii105-ii106.

Von Hoff DD, Ervin T, Arena FP, Chiorean EG, Infante J, Moore M, Seay T, Tjulandin SA, Ma WW, Saleh MN, Harris M, Reni M, Dowden S, Laheru D, Bahary N, Ramanathan RK, Tabernero J, Hidalgo M, Goldstein D, Van Cutsem E, Wei X, Iglesias J, Renschler MF (2013) Increased survival in pancreatic cancer with nab-paclitaxel plus gemcitabine. N Engl J Med 369: 1691-1703.

Yoo C, Hwang JY, Kim J-E, Kim TW, Lee JS, Park DH, Lee SS, Seo DW, Lee SK, Kim M-H, Han DJ, Kim SC, Lee J-L (2009) A randomised phase II study of modified FOLFIRI.3 vs modified FOLFOX as second-line therapy in patients with gemcitabine-refractory advanced pancreatic cancer. Br J Cancer 101: 1658-1663.

Zaanan A, Trouilloud I, Markoutsaki T, Gauthier M, Dupont-Gossart A-C, Lecomte T, Aparicio T, Artru P, Thirot-Bidault A, Joubert F, Fanica D, Taieb J (2014) FOLFOX as second-line chemotherapy in patients with pretreated metastatic pancreatic cancer from the FIRGEM study. BMC Cancer 14: 441.

This work is published under the standard license to publish agreement. After 12 months the work will become freely available and the license terms will switch to a Creative Commons AttributionNonCommercial-Share Alike 4.0 Unported License.

Supplementary Information accompanies this paper on British Journal of Cancer website (http://www.nature.com/bjc) 